\title{
Importation of ornamental plants facilitates establishment of the Common House Gecko, Hemidactylus frenatus Duméril \& Bibron, in the Lesser Antilles
}

\author{
Jeanelle L. K. Brisbane' ${ }^{1 D}$, Maël Dewynter ${ }^{2}\left(\mathbb{D}\right.$, Baptiste Angin ${ }^{3}{ }^{D}$, Karl Questel ${ }^{4}$, and Matthijs P. van \\ den Burg ${ }^{5,6 *}$ (ID)
}

'WildDominique, Roseau, Commonwealth of Dominica.

${ }^{2}$ Société Maël Dewynter, Matoury, French Guyana.

${ }^{3}$ Ardops Environnement, Les Abymes, Guadeloupe.

${ }^{4}$ Agence Territoriale de L’Environnement de Saint-Barthélemy, Rue de la Republique, Gustavia 97133, Saint Barthélemy.

${ }^{5}$ Department of Biogeography and Global Change, Museo Nacional de Ciencias Naturales, Consejo Superior de Investigaciones Científicas, Calle José Gutiérrez Abascal 2, Madrid 28006, Spain.

${ }^{6}$ Current address: BioCoRe S. Coop., Calle Villagarcía 6, Madrid 28010, Spain.

"Corresponding author (thijs.burg@gmail.com)

Edited by: R. Graham Reynolds. Date of publication: 17 June 2021.

Citation: Brisbane JLK, Dewynter M, Angin B, Questel K, van den Burg MP (2021) Importation of ornamental plants facilitates establishment of the Common House Gecko, Hemidactylus frenatus Duméril \& Bibron, in the Lesser Antilles. Caribbean Herpetology, 77, 1-5.

DOI: https://doi.org/10.31611/ch.77

The Asian Hemidactylus frenatus is globally among the most widespread non-native species (Rödder et al. 2008; Torres-Carvajal 2015; Wetering \& Vetter 2018) and has recently been reported from multiple novel localities, including within the Greater Caribbean region (Sánchez 2018; Behm et al. 2019). Hemidactylus frenatus is well-known as an aggressive, invasive gecko that widely interacts with native geckos throughout its non-native range, mainly documented outside the Caribbean (e.g., Hoskin 2011). Namely, reports have repeatedly described how $H$. frenatus (1) competitively displaces native species (e.g., Cole et al. 2005), although some accounts show native species persisting (Cisterne et al. 2019; Garner et al. 2020), and (2) are known to consume small reptilian species (see species account on GISD [2020] for an overview). Although geckos in the genus Hemidactylus can occasionally serve as prey for native species in the Caribbean (Reynolds et al. 2020), the detrimental effects of $H$. frenatus on native species highlight the need to monitor its spread closely and rapidly circulate information on novel establishments among local and regional partners. Evidently, there is an increased need for studies into the interactions between non-native and native geckos in the Greater Caribbean region (Perella \& Behm 2020).

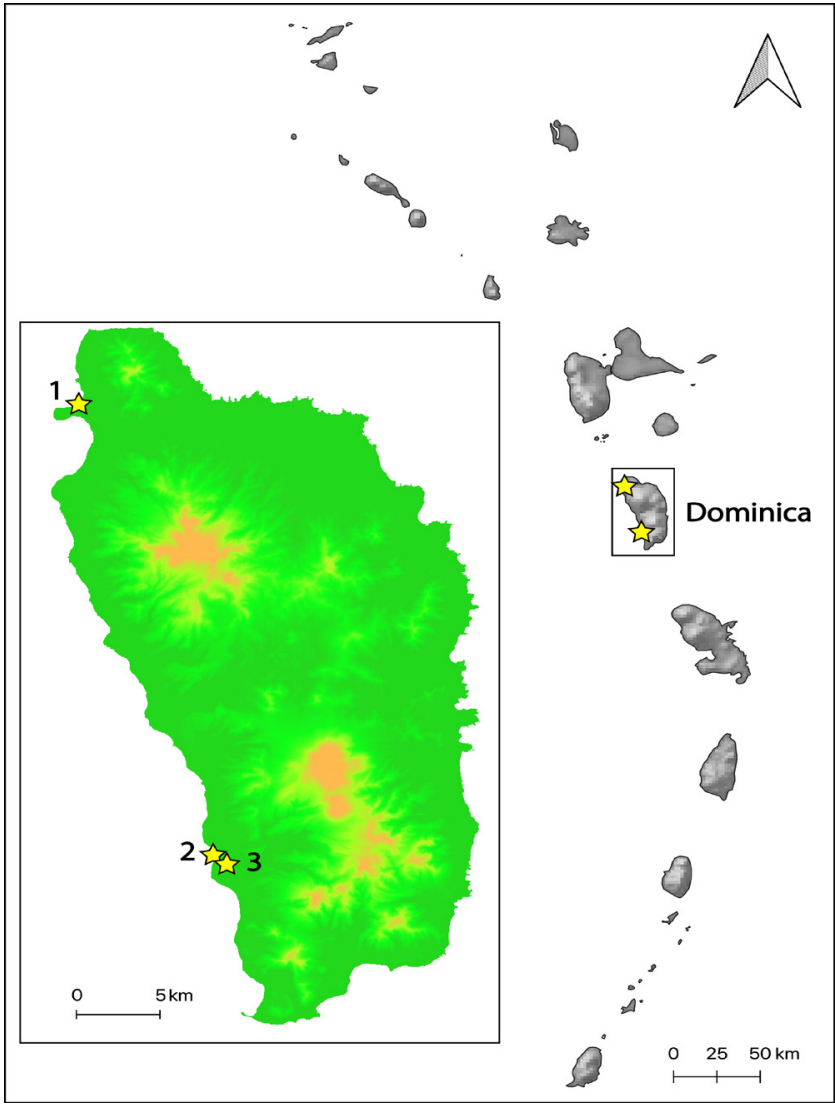

Since the passing of Hurricane Maria (a Saffir-Simpson Category 5 Atlantic storm) over Dominica in September 2017, repeated surveying efforts have Figure 1. Map of the Commonwealth of Dominica indicating locations
(stars) where Hemidactylus frenatus has been observed; 1) Resort north
of Portsmouth, 2) Woodbridge Bay Port, 3) Roseau. 
aimed to assess its impact on native species and the occurrence of non-native species. These efforts have already indicated anthropogenic-facilitated incursion of two well-known invasive amphibians and reptiles (van den Burg et al. 2020a). Surveys encompassed $>70$ areas along the island's coast where most non-native species are known to occur, as well as in the interior, with only a few in the central interior and south-eastern coast.

On 10 October 2019 at 21:47 h, the first $H$. frenatus was observed and captured on Dominica, at a recently-constructed resort near the northern town of Portsmouth (15.5913, -61.4643; Figs. 1, 2). In total, seven adult individuals were observed over a 3-hour nocturnal period at two sites (268 $\mathrm{m}$ apart); one on the main fencing of the hotel grounds, and, six on temporary construction houses on the opposite side of the road. This area was used as storage for imported construction materials and ornamental plants. Individuals were observed hunting on insect prey around artificial light at night. A single female $H$. frenatus was captured and held captive in a holding container for taxonomic identification purposes, where it laid two eggs.

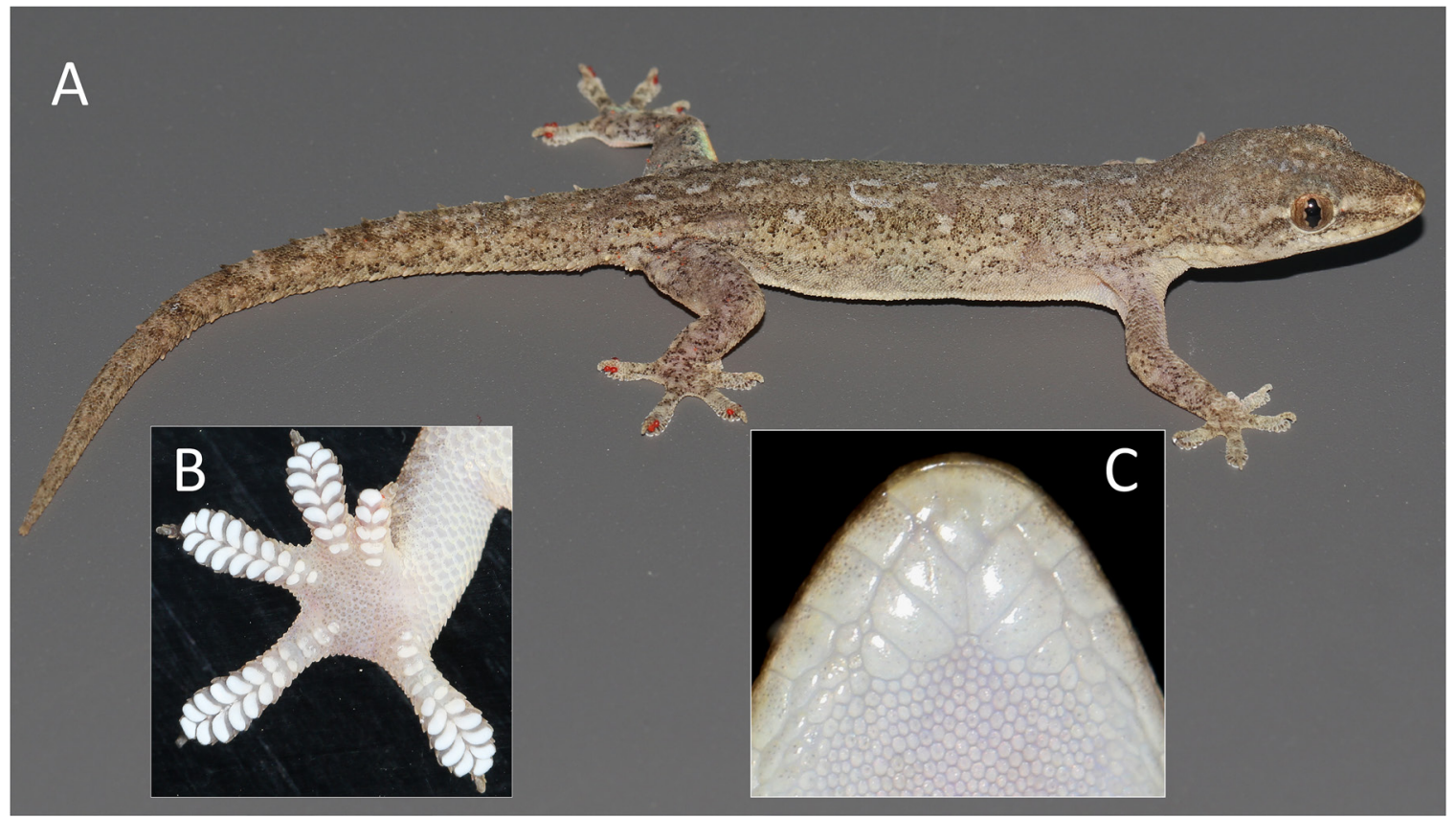

Figure 2. Hemidactylus frenatus captured in January 2020 on Dominica [Fig. 1; location 1]. Pictures shown following key in Krysko and Daniels (2005). (A) Dorsal side of specimen with few and small tubercles, showing high number of ectoparasites on the hind toes and the base of the tail; (B) ventral side of feet with subdigital lamellae of digit IV running to base of the digit; (C) ventral side of chin, with second pair of anterior chin shields in contact with infralabials. Photographs taken by Maël Dewynter.

Since then, observations have indicated $H$. frenatus presence from two additional sites. On 10 September 2020 at 20:04 h, a group of $H$. frenatus was discovered on the grounds of Dominica's main seaport (Woodbridge Bay Seaport; 15.3117,-61.3891; Fig. 1). A total of 11 individuals were observed, constituting five adults and six juveniles, of which one of the latter was captured for taxonomic identification. These animals were located around the storage houses. Collectively, another four individuals have since been discovered in a two-block radius within the capital of Roseau (Fig. 1); three adults and one juvenile. At all sites, both $H$. frenatus and H. mabouia were present, either in equal numbers or with higher $H$. frenatus presence.

The $H$. frenatus incursion is believed to have been facilitated through a shipment of 15-17 containers transporting ornamental plants to a resort north of Portsmouth from Florida (USA), where it is a known invasive species (Weterings \& Vetter 2017), in June 2019. Through direct observations and subsequent interviews (pers. obs. JLKB), it became known that numerous non-native fauna were imported: arachnids, millipedes, and, other invertebrates, as well as Cuban treefrogs, and likely an Argentine black and white tegu (identified by an interviewee 
from internet-based images). Contrary to biosecurity guidelines, these containers were not initially opened and checked at the Woodbridge Bay Port (although temporarily stored there) but only opened once on the resort's grounds. The temporary storage at the port of entry can explain the presence of a small population there. Additionally, we note the seemingly high parasitic load of the caught individual (Fig. 2), the overspill of which to native species is a concern as highlighted by other studies (Miller et al. 2018). Overall, this note found established and small breeding populations of Hemidactylus frenatus on Dominica, making it the 11th non-native established vertebrate on the island and the 3rd established non-native amphibian and reptile since the passage of Hurricane Maria in 2017 (van den Burg et al. 2020a; GISD 2020).

To better understand the Lesser Antillean spread of $H$. frenatus, we examined observational records on the online platform iNaturalist (van den Burg et al. 2020b). Given that species of Hemidactylus can be hard to distinguish (Krysko \& Daniels 2005), we assessed all Hemidactylus records between Anguilla and Grenada; in total 81 records: 77 H. mabouia (Moreau de Jonnès), and two for both H. frenatus and H. palaichthus Kluge. Hemidactylus frenatus is reported from Guadeloupe (French West Indies, iNaturalist record \#5560475) and St. Lucia (iNaturalist record \#37074494). Although image quality was generally low and often solely taken from the dorsal side, our examination indicated that at least the Guadeloupe H. frenatus record is in fact an H. mabouia; based on the presence of a clear line between the eyes and the presence, number, and placement of the dorsal tubercles (Krysko \& Daniels 2005). Although the main criteria used to diagnose species of Hemidactylus are the subdigital lamellae of toe IV (extended or not at the base), this character was not visible. Both image quality and the body angle of the St. Lucia record prevented definitive species identification, but given the species has not been officially recorded from the region, expert judgement favours $\mathrm{H}$. mabouia in the absence of proper specimen assessment. Indeed, the taxonomic suggestion was made by iNaturalist (pers. comm. D. Wolfe), which can be erroneous (Wäldchen \& Mäder 2018). To confirm the presence of $H$. frenatus on St. Lucia, we suggest monitoring by scientists and local naturalists and/or herpetologists. Although iNaturalist assigns a "Research Grade" status to records for which several users agree on taxonomy; users cannot always assume correct taxonomic assignment, which should be confirmed ahead of data usage (see Hochmair et al. 2020).

The arrival of the Common House Gecko (H. frenatus) in the Lesser Antilles further emphasises the current high rate of gecko introductions in the Greater Caribbean region (Nania et al. 2020; Perella \& Behm 2020). As the common name suggests, this species is capable of living in anthropogenic habitats (Hoskin 2011; Muller et al. 2020), which promotes dispersal facilitated through cargo transport (Newberry \& Jones 2007). Also, as H. frenatus eggs are saltwater tolerant (Hsu et al. 2020), and can hatch after immersion, natural dispersal to neighbouring islands could be expected if these populations expand over Dominica. The spread of non-native vertebrates through the importation of ornamental plants, as reported here, is not uncommon (Hulme et al. 2008; Saul et al. 2016), and subsequent incursions from the same place of origin can be expected. We recommend stricter import legislation and its subsequent enforcement, especially during periods following natural disasters when biosecurity capacity is hampered (van den Burg et al. 2021). Furthermore, throughout the Lesser Antilles, we call for the promotion and use of native plant species when planning ornamental decoration (Tallamy 2007). Lastly, with the arrival of $H$. frenatus, we call for awareness among regional biosecurity personnel, in addition to monitoring efforts (both visual and acoustic; Hopkins et al. 2020) by regional partners, and education efforts in an attempt to prevent its further spread in the Lesser Antilles.

\section{Acknowledgements}

We thank the editor and two anonymous reviewers for their constructive feedback that improved an earlier version of this manuscript. Fieldwork was supported through grants from the GEF Small Grants Programme, The National Geographic Society (EC-55300-18), the International Iguana Foundation, Fauna and Flora International through the Caribbean Programme, the Mohamed Bin Zayed Species Conservation Fund (182518984), and Fond de 
Coopération Régional, Préfecture de Guadeloupe (n²019-21). We thank the Forestry, Wildlife and Parks Division for providing research permits.

\section{References}

Behm JE, van Buurt G, DiMarco BM, Ellers J, Irian CG, Langhans KE, et al. (2019) First records of the mourning gecko (Lepidodactylus lugubris Duméril and Bibron, 1836), common house gecko (Hemidactylus frenatus in Duméril, 1836), and Tokay gecko (Gekko gecko Linnaeus, 1758) on Curaçao, Dutch Antilles, and remarks on their Caribbean distributions. Biolnvasions Records, 8, 34-44. https://doi.org/10.3391/bir.2019.8.1.04

Cisterne A, Schwarzkopf L, Pike DA (2019) Australian house geckos are more aggressive than a globally successful invasive Asian house gecko. Behavioral Ecology, 30, 107-113. https://doi.org/10.1093/beheco/ary156

Cole NC, Jones CG, Harris S (2005) The need for enemy-free space: The impact of an invasive gecko on island endemics. Biological Conservation, 125, 467-474. https://doi.org/10.1016/j.biocon.2005.04.017

Garner AM, Pamfilie AM, Hamad EJ, Kindig R, Taylor JT, Unsworth CK, Niewiarowski PH (2020) Home-field advantage: native gecko exhibits improved exertion capacity and locomotor ability in structurally complex environments relative to its invasive counterpart. Frontiers in Zoology 17: 23. https://doi.org/10.1186/s12983020-00368-8

GISD (Global Invasive Species Database) (2020) Available at http://www.iucngisd.org/gisd/speciesname/Hemidactylus+frenatus. Accessed 5 October 2020.

Hochmair HH, Scheffrahn RH, Basille M, Boone M (2020) Evaluating the data quality of iNaturalist termite records. PLoS ONE, 15, e0226534. https://doi.org/10.1371/journal.pone.0226534

Hopkins JM, Higgie M, Hoskin CJ (2020) Calling behaviour in the invasive Asian house gecko (Hemidactylus frenatus) and implications for early detection. Wildlife Research, 48, 152-162. https://doi.org/10.1071/WR20003

Hoskin CJ (2011) The invasion and potential impact of the Asian House Gecko (Hemidactylus frenatus) in Australia. Austral Ecology, 36, 240-251. https://doi.org/10.1111/j.1442-9993.2010.02143.x

Hsu M-H, Lin J-W, Liao C-P, Hsu J-Y, Huang W-S (2021) Trans-marine dispersal inferred from the saltwater tolerance of lizards from Taiwan. PLOS ONE, 16, e0247009. https://doi.org/10.1371/journal.pone.0247009

Hulme PE, Bacher S, Kenis M, Klotz S, Kühn I, Minchin D, et al. (2008) Grasping at the routes of biological invasions: a framework for integrating pathways into policy. Journal of Applied Ecology, 45, 403-414. https://doi. org/10.1111/j.1365-2664.2007.01442.x

iNaturalist (2020) iNaturalist. Available from https://www.inaturalist.org/observations/. Accessed 5 October 2020.

Kluge AG (1969) The evolution and geographical origin of the New World Hemidactylus mabouia-brooki complex (Gekkonidae, Sauria). Miscellaneous publications, University of Michigan, Museum of Zoology, 138, 1-78.

Krysko KL, Daniels KJ (2005) A key to the geckos (Sauria: Gekkonidae) of Florida. Caribbean Journal of Science, 41, 28-36.

Miller MA, Kinsella JM, Snow RW, Hayes MM, Falk BG, Reed RN, et al. (2018) Parasite spillover: indirect effects of invasive Burmese pythons. Ecology and Evolution, 8, 830-840. https://doi.org/10.1002/ece3.3557

Moreau de Jonnès A (1818) Monographie du mabouja des murailles, on Gecko Mabouja des Antilles. Bulletin des Sciences par La Société Philomatique, 5, 138-139.

Muller BJ, Andrews RM, Schwarzkopf L, Pike DA (2020) Social context alters retreat - and nest - site selection in a globally invasive gecko, Hemidactylus frenatus. Biological Journal of the Linnean Society, 129, 388-397. https://doi.org/10.1093/biolinnean/blz188

Nania D, Flecks M, Rödder D (2020) Continuous expansion of the geographic range linked to realized niche expansion in the invasive Mourning gecko Lepidodactylus Igubris (Duméril \& Bibron, 1836). PLOS ONE, 15, e0235060. https://doi.org/10.1371/journal.pone.0235060 
Newberry B, Jones DN (2007) Presence of Asian House Gecko Hemidactylus frenatus across an urban gradient in Brisbane: influence of habitat and potential for impact on native gecko species. In: Pest or Guest: The Zoology of Overabundance (eds Lunney D, Eby P, Hutchings P \& Burgin S) p. 59-65. Royal Zoological Society of New South Wales, Mosman. http://doi.org/10.7882/FS.2007.009

Perella CD, Behm JE (2020) Understanding the spread and impact of exotic geckos in the greater Caribbean region. Biodiversity and Conservation, 29, 1109-1134. https://doi.org/10.1007/s10531-020-01939-1

Reynolds RG, Colosimo G, Peek K, Vanerelli A, Bradley K, Gerber GP (2020) Chilabothrus chrysogaster chrysogaster (Turks Island Boa). Diet. Herpetological Review, 51, 610-611.

Rödder D, Solé M, Böhme W (2008) Predicting the potential distributions of two alien invasive housegeckos (Gekkonidae: Hemidactylus frenatus, Hemidactylus mabouia). North-Western Journal of Zoology, 4, 236-246.

Sánchez A (2018) Discovery of the Common House Gecko, Hemidactylus frenatus (Duméril \& Bibron), in Puerto Rico. Caribbean Herpetology, 60, 1-2. https://doi.org/10.31611/ch.60

Saul W-C, Roy HE, Booy O, Carnevali L, Chen H-J, Genovesi P, et al. (2016) Assessing patterns in introduction pathways of alien species by linking major invasion data bases. Journal of Applied Biology, 54, 657-669. https:// doi.org/10.1111/1365-2664.12819

Tallamy DW (2007) Bringing nature home: how you can sustain wildlife with native plants. Timber Press, Inc., Portland, OR, USA.

Torres-Carvajal O (2015) On the origin of the South American populations of the common house gecko (Gekkonidae: Hemidactylus frenatus). NeoBiota, 27, 69-79. http://doi.org/10.3897/neobiota.27.5437

van den Burg MP, Brisbane JLK, Knapp CR (2020a) Post-hurricane relief facilitates invasion and establishment of two invasive alien vertebrate species in the Commonwealth of Dominica, West Indies. Biological Invasions, 22, 195-203. https://doi.org/10.1007/s10530-019-02107-5

van den Burg MP, Van Belleghem SM, De Jesús Villanueva CN (2020b) The continuing march of common green iguanas: arrival on mainland Asia. Journal for Nature Conservation, 57, 125888. https://doi.org/10.1016/j. jnc.2020.125888

van den Burg MP, Daltry JC, Angin B, Boman E, Brisbane JLK, Collins K, Haakonsson JE, Hill A, Horrocks JA, Mukhida F, Providence F, Questel K, Ramnanan N, Steele S, Vique Bosquet IM, Knapp CR (2021) Biosecurity for humanitarian aid. Science, 372, 581-582. https://doi.org/10.1126/science.abj0449

Wäldchen J, Mäder P (2018) Machine learning for image based species identification. Methods in Ecology and Evolution, 9, 2216-2225. https://doi.org/10.1111/2041-210X.13075

Wetering R, Vetter KC (2018) Invasive house geckos (Hemidactylus spp.): their current, potential and future distribution. Current Zoology, 64, 559-573. https://doi.org/10.1093/cz/zox052 